\title{
Espacio social y democracia
}

\begin{abstract}
A través de este número, nos gustaría explicar un espacio social polivalente producido en el hecho de la democracia universitaria, y que florece en Estoa por el conocimiento generado desde múltiples ámbitos de la investigación urbanoarquitectónica.

"Gobierno del pueblo" es el significado que más se acerca al origen etimológico de la palabra democracia, pero ¿cuántas democracia caben en el espacio? y ¿cuál es el rol de esos lugares en la práctica democrática? Si asimilamos al menos cuatro formas democráticas con características propias y traducción en el espacio, pensaríamos de menos a más, en una Democracia parcial perpetrada en despachos, oficinas y salas ejecutivas, incluso en espacios de culto; y claro, en la plenamente reconocida Democracia representativa, formalizada en palacios presidenciales, parlamentos, recintos electorales y salas de consejos. Pero también podemos reconocer formas democráticas más participativas, que alcanzan plazas y parques, auditorios foros de socialización, aunque allí la cuota de participación todavía está condicionada por agentes de representación. Estos límites nos conducen a mirar con atención a la más antigua de las democracias, aquella concebida como Directa, que desprendida de cánones liberales se configura en el espacio urbano o la calle como su expresión más notable, pero también en centros de barrio, definidos por la espontaneidad de los encuentros vecinales o comunitarios. Entonces, se entiende que una democracia directa en la escala de lo urbano engendra al espacio social en su máxima expresión. Siendo así, la noción de "espacio social" es algo que nos vemos obligados a esclarecer en esta editorial. Para ello nos apoyamos, de modo sumario, en el trabajo de Henri Lefebvre La producción del espacio (1974).
\end{abstract}

El espacio social es el espacio de la sociedad, de la vida social. El hombre no vive únicamente por la palabra, decía Lefebvre. Cada sujeto se sitúa en un espacio donde se reconoce o se pierde: un espacio para gozar o modificar. El espacio social no es una cosa entre las cosas, un producto cualquiera entre los productos. Más bien, envuelve a las cosas producidas y comprende sus relaciones en su coexistencia y simultaneidad, en su orden y/o desorden relativos. En tanto que resultado de una secuencia y de un conjunto de operaciones, no puede reducirse a la condición de simple objeto. Como efecto de acciones pasadas, el espacio social permite que tengan lugar determinadas acciones, sugiriendo unas y prohibiendo otras. Unas acciones remiten al universo de la producción, otras a disfrute de los productos, es decir, al consumo.

Así, el espacio social implica múltiples conocimientos, por lo que ni la naturaleza o el medio físico, ni su historia, pueden aclararlo suficientemente. Ni siquiera la cultura, en tanto que alienada por el mundo de las mercancías y reductora de la teoría de la producción del espacio. Para el teórico francés, el espacio social contiene objetos muy diversos, tanto naturales como sociales, incluyendo redes $y$ ramales que facilitan el intercambio de artículos e informaciones. Por ello, no se reduce ni a los objetos que contiene ni a su mera agregación, ya que tales objetos no son únicamente cosas sino también relaciones. Entonces, el espacio es asímismo una relación social que manifiesta su polivalencia, su realidad a la vez formal material, como un producto que se utiliza y se consume, y también como medio de producción, por las redes y flujos que lo determinan y que son determinados por él.

A la luz de la democracia en la universidad pública, nos situamos en aquellas formas de representación que producen el espacio en recintos eleccionarios y consejos diversos. Esta cualidad del espacio electoral es repetitiva por regla, y sin embargo puede alterarse bajo condiciones inéditas, como la voluntad de ejercer la democracia en el contexto de una pandemia global que ataca las funciones de proximidad física. Así pues, saldremos a votar por restringida que esté nuestra congregación en el espacio. Otro signo del ejercicio democrático se produce cuando la comunidad que conforma la universidad decide volcarse a las calles para reivindicar (con la sociedad) el respeto por sus derechos a una educación pública de calidad. Entonces, esta fluidez de las relaciones sociales, que mutan a nuevas formas de espacios democráticos en el quehacer universitario dan cuenta de la versatilidad del espacio social como tal.
Este 2021, Estoa abre con catorce nuevos artículos en su afán de divulgar los avances del conocimiento relativo al espacio urbano y arquitectónico; avances que implican una fuerza productiva del espacio social, dando respuesta a un conjunto de interrogantes y desafíos en los ámbitos de la enseñanza de la arquitectura, los estudios urbanos, la conservación del patrimonio cultural edificado, y la eficiencia constructiva y energética.

Solano Meneses se cuestiona sobre las implicaciones de las ciencias cognitivas en el diseño arquitectónico inclusivo. Siguiendo est línea, Martínez-Vitor y Salva-Pérez se plantean en qué medida la aceptación o rechazo de un proyecto arquitectónico se produce por la vinculación de las emociones y sentimientos del aprendizaje con el proceso de deliberación sensitiva del proyecto. GranadosManjarrés se pregunta cómo cambiar el statu quo del taller en la enseñanza del proyecto arquitectónico. Real Ramos y Yunda plantean la efectividad de implementar el sistema de Aprendizaje Basado en el Juego en la enseñanza de arquitectura para responder ante los retos de desinterés y falta de concentración de los estudiantes. Bravo de Laguna Socorro indaga en las oportunidades pedagógicas y experimentales que ofrece la colección de siete juegos de cartas sobre arquitectura. Y el trabajo de Hernández Sánchez y De la Torre Sánchez, pone a prueba las estrategias que pueden desplegarse desde proyectos académicos en las escuelas de arquitectura para resolver problemáticas integración social en la ciudad.

En el campo de los estudios urbanos, Períes, Barraud y Kesman se centran en la profundización de una metodología y técnicas para la caracterización de componentes paisajísticos para la construcción de catálogos de paisaje urbano. Arredondo Garrido identifica unas claves para la recuperación del paisaje cultural de la Vega de la Granada, aprovechando sus espacios de transición. Fernández Villalobos y Jiménez Sanz revelan las relaciones que esconde la Capilla del Bosque de Heikki y Kaija Siren con el lugar y su representación en otros espacios religiosos; y Bueno Carvajal se interroga acerca de los enfoques bajo los cuales podemos comprender la identidad urbana para el análisis de la ciudad contemporánea a través de su espacio público.

En la línea del patrimonio cultural edificado, Ortega y Pérez V. se cuestionan sobre cómo ha incidido el Plan Regulador Comunal de Santiago de Chile en la conservación del patrimonio construido de la ciudad; y Juca Freire plantea la capacidad de la gobernanza participativa del patrimonio para convertirse en un medio efectivo de empoderamiento de las comunidades hacia la sostenibilidad. Por último, desde el ámbito de las construcciones y la eficiencia energética, Socarrás-Cordoví, Álvarez-Deulofeu y Lora-Alonso resuelven la necesidad de pronosticar los cambios en el comportamiento sísmico de edificaciones construidas con el gran panel soviético; y Wieser, Rodríguez-Larraín y Onnis desarrollan un prototipo que permite definir las estrategias bioclimáticas para obtener el confort térmico en la vivienda altoandina del Perú.

Así resulta que, operando en la geografía pública de la democracia universitaria, la revista Estoa se declara pilar en la producción del espacio social, desde su contribución al florecimiento de conocimiento y las técnicas que involucran las posibilidades de progreso en el ámbito urbano-arquitectónico.
Pedro Jiménez-Pacheco pedro.jimenezp@ucuenca.edu.ec

Editor

Cuenca, enero de 2021 